\title{
PRONATEC E O MERCADO DE TRABALHO: UMA ANÁLISE PARA OS CURSOS OFERECIDOS NO IFRS CAMPUS RIO GRANDE
}

\author{
José Felipe Silva * \\ Gibran da Silva Texeira ${ }^{\dagger}$ \\ Vinícius Halmenschlager $\ddagger$ \\ Rafael Mesquita Pereira $\S$ \\ Régis Augusto Ely II
}

\begin{abstract}
Resumo
Este artigo tem por objetivo avaliar a efetividade do Pronatec sobre o salário de reinserção, tempo de emprego e empregabilidade dos trabalhadores que participaram dos cursos do programa no IFRS, campus Rio Grande, nos anos de 2013 e 2014. Para tanto, foi aplicado o método de Diferenças em Diferenças com os dados identificados da Relação Anual de Informações Sociais - RAIS para o período de 2011 a 2018. Os resultados apontam que os cursos do Pronatec oferecidos pelo IFRS - campus Rio Grande, no período destacado, não geraram efeitos sobre as dimensões avaliadas, indicando assim, a falta de efetividade do programa.
\end{abstract}

Palavras-chave: políticas públicas, qualificação profissional, Pronatec, DID. Códigos JEL: C22, J08, J24.

\begin{abstract}
This article aims to evaluate the effectiveness of Pronatec on the reintegration salary, time of employment and employability of workers who participated in the program courses at IFRS, campus Rio Grande, in the years 2013 and 2014. For that, the method of differences in differences was applied with the data identified from the Relação Anual de Informações Sociais - RAIS for the period from 2011 to 2018. The results indicate that the Pronatec courses offered by IFRS - campus Rio Grande, in the mentioned period, did not generate effects on the dimensions evaluated, thus indicating the lack of effectiveness of the program.
\end{abstract}

Keywords: public policies, professional qualification, Pronatec, DID. JEL codes: C22, J08, J24.

DOI: http://dx.doi.org/10.11606/1980-5330/ea149391

\footnotetext{
*Universidade Federal do Rio Grande. E-mail: j_felipeds@yahoo.com.br.

† Universidade Federal do Rio Grande. E-mail: tgibran@hotmail.com.

‡ Universidade Federal do Rio Grande do Sul. E-mail: viniciush@ufrgs.br.

$\S$ Universidade Federal do Rio Grande. E-mail: rafaelmesquita@furg.br.

II Universidade Federal de Pelotas. E-mail: regisaely@gmail .com.
} 


\section{Introdução}

No início dos anos 2000, em virtude da descoberta do Pré-Sal no Brasil pela empresa Petróleo Brasil/SA, Petrobras, uma série de investimentos em infraestrutura foi realizada com a finalidade de promover a exploração, armazenamento e refino de petróleo, com destaque para os estados do Rio Grande do Sul, Santa Catarina, Pernambuco, Rio de Janeiro e Bahia, os chamados polos navais regionais, fomentados pelo Programa de Mobilização da Indústria Nacional de Petróleo e Gás Natural - PROMINP. No Rio Grande do Sul, a região sul acabou concentrando grande parte desses investimentos, principalmente por apresentar um ambiente portuário apropriado, que possibilitou a instalação de três estaleiros, o inicialmente denominado QUIP e logo após QGI, formado pelas empresas Queiroz Galvão e Iesa Óleo e Gás, o complexo naval Estaleiro Rio Grande-ERG (ERG I e ERG II), operado pela empresa Engevix/Ecovix-Engenharia e o estaleiro EBR da empresa Estaleiro Brasil. Em conjunto, esses três empreendimentos acabaram por confeccionar, parcialmente, oito, plataformas de petróleo, o que fomentou a economia do sul do RS (Cunha \& Rückert 2017, Lima et al. 2018, Teixeira et al. 2016).

Um dos principais gargalos ao desenvolvimento regional à época era a falta de mão de obra qualificada, isso acabou mobilizando uma rede de cursos profissionalizantes de natureza pública e privada. Mais especificamente nos anos de 2013 e 2014, uma série de cursos profissionalizantes foi oportunizada por meio do Programa Nacional de Acesso ao Ensino Técnico- Pronatec, realizados pelo Instituto Federal de Educação, Ciência e Tecnologia do Rio Grande do Sul (IFRS), no Campus Rio Grande, gerado por meio de uma parceria do Governo Federal e do município do Rio Grande. Os cursos foram ofertados na modalidade de Formação Inicial e Continuada (FIC), com 615 vagas, ao custo estimado de $\mathrm{R} \$ 1,09$ milhões.

Em âmbito internacional, a importância da qualificação profissional e a forma de se avaliar cursos, como os destacados, podem ser encontradas em autores como Friedlander et al. (1997), Greenberg (2003), Heckman et al. (1999), Kluve (2006), Lechner \& Melly (2007) e Martin \& Grubb (2001) que, com base em técnicas econométricas, procuram identificar o impacto dos programas, sobretudo em inserção profissional (empregabilidade), capital humano e ganhos salariais. As avaliações se tornam relevantes, pois a partir das análises de desempenhos dos beneficiados é possível identificar questões que devem ser realinhadas ou mesmo modificadas no âmbito do direcionamento das políticas de qualificação profissional.

Em particular, com base nos resultados de Heckman et al. (1999) e Kluve (2006), têm-se efeitos modestos de cursos de qualificação profissional sobre ganhos salariais nos Estados Unidos e Europa. Para o caso da América Latina, Betcherman et al. (2004) e Ibarrarán \& Shady $(2009)^{1}$ indicam que os resultados dos cursos de capacitação profissional, em termos de ganhos salariais, são melhores do que em países desenvolvidos. Isso pode estar associado ao

\footnotetext{
${ }^{1}$ Na América Latina, por exemplo, Ibarrarán \& Shady (2009) realizaram uma compilação de estudos que avaliaram a eficiência desse tipo de política em sete países latinos: duas avaliações com um projeto experimental (República Dominicana e Colômbia), uma com experiência natural (Panamá) e quatro avaliações não experimentais (Argentina, Chile, Peru e México). Em geral, os autores não identificaram um padrão de resultados com relação à eficiência dos programas. Os efeitos no emprego variaram de nulo, na Argentina e na República Dominicana, a significante e positivo na maioria dos demais países.
} 
fato de que o efeito qualificação profissional pode dar um sinal maior sobre a produtividade do trabalhador em países onde a mão de obra média possui baixa qualificação.

Mais especificamente para o caso brasileiro, estudos recentes como os desenvolvidos por Barbosa Filho et al. (2016), Corseuil et al. (2018), Firpo et al. (2014), Lima et al. (2020), Oliveira et al. (2019), Teixeira et al. (2020), Teixeira \& Balbinotto Neto (2016), além de Fernandes et al. (2000), que aplicam estratégias de identificação com base em metodologias para quase-experimentos, ainda são relativamente escassos, muito pela indisponibilidade de informações ou falta de motivação institucional, fato este que impossibilita, na maioria das vezes, o aperfeiçoamento de políticas de qualificação profissional no Brasil. Esse fator acaba sendo preponderante, haja vista que, como destacado por Camargo (2004), a preocupação com o desenho dos programas é tão importante quanto a sua própria existência.

Nesse contexto, a pesquisa busca contribuir para o entendimento e o direcionamento dos efeitos gerados pelos Cursos FIC, disponibilizados via Pronatec e ministrados no IFRS, Campus Rio Grande, ao avaliar se os mesmos atenderam aos pressupostos da concepção da política, que visam, por meio da qualificação profissional, melhorar a reinserção no mercado de trabalho e, consequentemente, promover maior probabilidade de reinserção formal, ganhos salariais e tempo de permanência no emprego, entre os seus beneficiados. Para realizar essa análise, foram utilizados os dados identificados da Relação Anual de Informações Sociais - RAIS, no período de 2011 a 2018, em conjunto com as informações disponibilizadas pelo IFRS, Campus Rio Grande, dos trabalhadores que foram selecionados para participarem dos cursos profissionalizantes na modalidade FIC oferecidos nos anos de 2013 e 2014, via Pronatec.

A fim de estimar o efeito médio dos cursos de qualificação profissional oferecidos pelo IFRS sobre os beneficiários, este estudo usou como metodologia a abordagem de quase experimentos, em especial o método de Diferenças em Diferenças, com distintas especificações. A análise contemplou a organização de um painel de dados de indivíduos com informações da RAIS e do IFRS. Foram utilizadas quatro especificações, sendo elas: (i) estimadores para dados em painel com controle de efeito-fixo de indivíduo e de tendência temporal; (ii) estimadores para dados em painel com controle de efeito-fixo de indivíduos, tendência temporal e covariadas; (iii) estimadores para dados em painel com controle de efeito-fixo de indivíduos, tendência temporal, covariadas e efeitos heterogêneos de exposição após ao tratamento; e (iv) estimadores desenvolvidos a partir de pareamento amostral em variáveis observáveis no período pré-tratamento.

Os resultados encontrados indicam que os cursos de qualificação profissional ofertados pelo IFRS, Campus Rio Grande, na modalidade FIC, não apresentaram nenhum efeito sobre as variáveis analisadas. Um fator que pode estar influenciando esse resultado é o arrefecimento do mercado de trabalho regional, em função da queda do segmento naval no Brasil, gerando uma alteração na dinâmica da demanda por mão de obra regional e local e, assim, reduzindo as chances de inserção dos trabalhadores treinados. No entanto, os resultados são corroborados por Barbosa Filho et al. (2016), que avaliaram o Pronatec em escala nacional, para os trabalhadores treinados em 2011 e reinseridos no mercado de trabalho entre 2012 e 2013. Algo semelhante também foi encontrado por Oliveira et al. (2019) que, usando um painel de jovens 
beneficiários de um programa de qualificação profissional em Goiás (Bolsa Futuro), com estratégia de identificação semelhante ao usado no presente estudo, ao compará-los em relação aos não beneficiários do programa e também aos alunos treinados pelo Pronatec, não encontraram efeito sobre salários de reinserção, somente sobre a probabilidade de inserção no mercado de trabalho formal.

Como destacado por Oliveira et al. (2019), por mais que existam trabalhos que avaliem programas de qualificação profissional no Brasil, ainda há uma carência de estudos que indiquem o real efeito desses sobre o mercado de trabalho, particularmente no que tange à valorização destes pelo lado dos empregadores. Em nível regional e local, essa escassez ainda é mais evidente, muito pela falta de transparência das instituições públicas em divulgar informações sobre custos de treinamento, grupos treinados, forma de treinamento e também pela ainda incipiente cultura de avaliação de desempenho, algo que se torna de fundamental importância para o uso e a aplicação eficiente dos recursos públicos.

Este artigo está dividido em cinco seções, incluindo esta introdução. A seção 2 apresenta o Pronatec e o caso para o sul do Rio Grande do Sul. A seção 3 descreve a amostra e também a estratégia de identificação utilizada. A seção 4 apresenta e discute os resultados obtidos. Por fim, a seção 5, retrata as considerações finais do estudo.

\section{O Pronatec e o Sul do Rio Grande do Sul}

O Programa Nacional de Acesso ao Ensino Técnico e Emprego - Pronatec foi instituído pela Lei 12.513, de 26 de outubro de 2011, como parte de um conjunto de ações que visavam ampliar a oferta de educação profissional e tecnológica, por meio de programas, projetos e ações de assistência técnica e financeira (Brasil 2011). Tal Lei elenca cinco objetivos do Pronatec: (i) expansão, interiorização e democratização de cursos de educação profissional de nível médio e programas de formação inicial e continuada ou qualificação profissional; (ii) fomento à expansão da rede física de atendimento da educação profissional e tecnológica; (iii) contribuir com a melhoria da qualidade do ensino médio público em articulação com a educação profissional; (iv) ampliar as oportunidades educacionais dos trabalhadores, por meio do incremento da formação e qualificação profissional; e (v) estimular a difusão de recursos pedagógicos para apoiar a oferta de cursos de educação profissional e tecnológica;

A referida Lei trata, ainda, que o Pronatec tem como prioridade: (i) estudantes do ensino médio da rede pública, inclusive da educação de jovens e adultos; (ii) trabalhadores em geral; (iii) beneficiários dos programas federais de transferência de renda; e (iv) estudantes que tenham cursado o ensino médio completo em escola da rede pública ou em instituições privadas na condição de bolsista integral. O programa prevê a participação voluntária dos serviços nacionais de aprendizagem, de instituições públicas e privadas de ensino superior, de instituições de educação profissional e tecnológica e de fundações públicas de direito privado principalmente dedicadas à educação profissional e tecnológica, como unidades concedentes dos cursos. Estas devem atender prioritariamente os estudantes do ensino médio da rede pública, trabalhadores, beneficiários dos programas federais de transferência de renda 
e estudantes que tenham cursado o ensino médio completo em escola da rede pública ou em instituições privadas na condição de bolsista integral. O levantamento das necessidades e a seleção dos participantes, articulando o público alvo com as instituições concedentes, devem ficar a cargo das unidades demandantes, como o Governo Federal e Secretarias Municipais.

O desenvolvimento do programa pode ocorrer de diversas formas: (i) com a criação de vagas, (ii) oferta de bolsa-formação, (iii) financiamento ou articulação com o Sistema Nacional de Emprego (SINE) e (iv) o Programa Nacional de Inclusão de Jovens (Projovem). A legislação estabelece como modalidades de educação profissional e tecnológica os cursos FIC com carga horária mínima de 160 (cento e sessenta) horas, os cursos de educação profissional técnica de nível médio e os cursos de formação de professores em nível médio na modalidade normal. No caso específico da bolsa-formação, esta é uma iniciativa que visa possibilitar o acesso a cursos presenciais, a serem realizados pela Rede Federal de Educação Profissional, Científica e Tecnológica, por escolas estaduais de ensino profissionalizante e técnico e por unidades de serviços nacionais de aprendizagem integrantes do Sistema S (Cassiolato \& Garcia 2014).

A lei de criação do Pronatec trouxe, também, uma alteração para a legislação correspondente ao Seguro-Desemprego, abrindo a possibilidade de condicionar o recebimento da assistência financeira do programa à comprovação da matrícula e da frequência do trabalhador em curso de formação inicial e continuada ou qualificação profissional (Brasil 2011). Ou seja, ao solicitar o benefício, o trabalhador poderia ser matriculado em um curso do programa e teria a permanência no curso como requisito para continuar segurado, algo como ressaltado por Teixeira et al. (2020). Esses cursos, em grande parte dos municípios, foram promovidos pela Rede Federal de Educação Profissional e Tecnológica retratada a partir da Figura 1 a seguir.

Figura 1: Instituições da Rede Federal de Educação Tecnológica

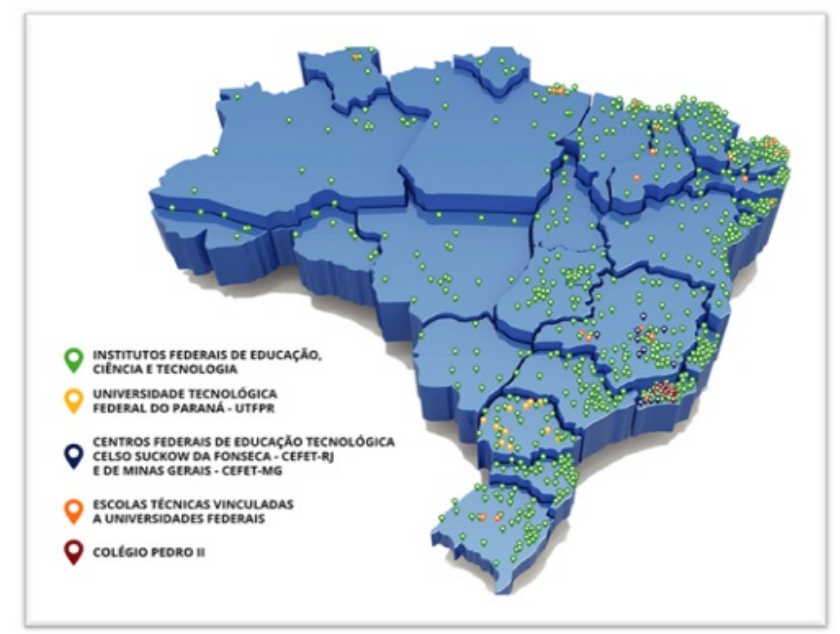

Fonte: Ministério da Educação - MEC.

No Rio Grande do Sul, segundo dados do portal do Ministério da Educação - MEC (2020), existem seis Instituições de Ensino Tecnológico, quarenta e um Campus e três Colégios Técnico-Industrial. De acordo com Silva (2016), mui- 
tos dos estudantes capacitados pelo PRONATEC foram treinados em Campus dessas Instituições. Além disso, a autora destaca que o número de vagas para o Brasil e também para o RS teve uma expansão acentuada nos anos de 2013 e 2014, como pode ser observado a partir da Tabela 1.

Tabela 1: Número de Vagas do Pronatec no Rio Grande do Sul

\begin{tabular}{c|c|c|c|c}
\hline Ano & Pré-Matrículas RS & \multicolumn{2}{c}{ Matrículas RS } & \multicolumn{2}{c}{ Concluintes RS } & Vagas Brasil \\
\hline 2011 & 241 & 219 & 5 & 966.972 \\
\hline 2012 & 69.230 & 64.737 & 21.529 & 1.802 .957 \\
\hline 2013 & 70.934 & 68.223 & 40.205 & 2.854 .208 \\
\hline 2014 & 99.726 & 89.924 & 37.528 & 3.104 .936 \\
\hline Total & $\mathbf{2 4 0 . 1 3 1}$ & $\mathbf{2 2 3 . 1 0 3}$ & $\mathbf{9 9 . 2 6 7}$ & $\mathbf{8 . 7 2 9 . 0 7 3}$ \\
\hline
\end{tabular}

Fonte: Adaptado de Silva (2016).

De acordo com a Tabela 1, é possível observar que o programa alcançou, em 2014, a marca de mais de três milhões de vagas espalhadas pelo território nacional. Considerando o número de pré-matrículas o RS, foi contemplado com cerca de 3,5\% desse total. A Tabela 2, a seguir, ressalta que apesar de a expansão da Rede Federal de Educação Profissional, Científica e Tecnológica ser uma das políticas consideradas como parte das ações integradas do Pronatec, no RS, o predomínio das vagas ofertadas foi do Sistema S, em especial pelo SENAC, porém a participação da Rede Federal também pode ser vista como relevante, ficando em segundo lugar na oferta das vagas.

Tabela 2: Instituições da Rede Federal de Educação Tecnológica

\begin{tabular}{c|c}
\hline Rede Ofertante & Percentual no RS \\
\hline Federal & $36,30 \%$ \\
Senat & $3,20 \%$ \\
Senai & $8,40 \%$ \\
Senac & $52,10 \%$ \\
\hline
\end{tabular}

Fonte: Adaptado de Silva (2016).

De acordo com a Tabela 2, entre 2011 e 2014, 63,7\% das vagas de cursos de formação inicial e continuada no Rio Grande do Sul foram ofertadas pelo Sistema S. Destas, 52,1\% pelo SENAC, enquanto que a rede federal foi responsável por $36,3 \%$ das vagas. Um desses polos de oferta de qualificação profissional da Rede Federal é do Instituto Federal de Educação, Ciência e Tecnologia do Rio Grande do Sul (IFRS), Campus Rio Grande, situado no sul do RS, no município do Rio Grande, e motivado, principalmente, pela demanda por mão de obra qualificada gerada, à época, pelos quatro grandes estaleiros instalados nas duas margens do Porto do Rio Grande, margem oeste pertencente ao município do Rio Grande e margem leste ao município de São José do Norte, conforme ressaltado na Figura 2, abaixo.

Com base em Cunha \& Rückert (2017), Lopo (2015), e Domingues et al. (2008), é possível identificar que o início da construção naval no município do Rio Grande se deu em meados de 2006 com a elaboração da infraestrutura necessária para a realização das atividades de montagem dos módulos e blocos que seriam construídos para a conversão do navio-petroleiro Settebelo 
Figura 2: Localização do Polo Naval do Rio Grande

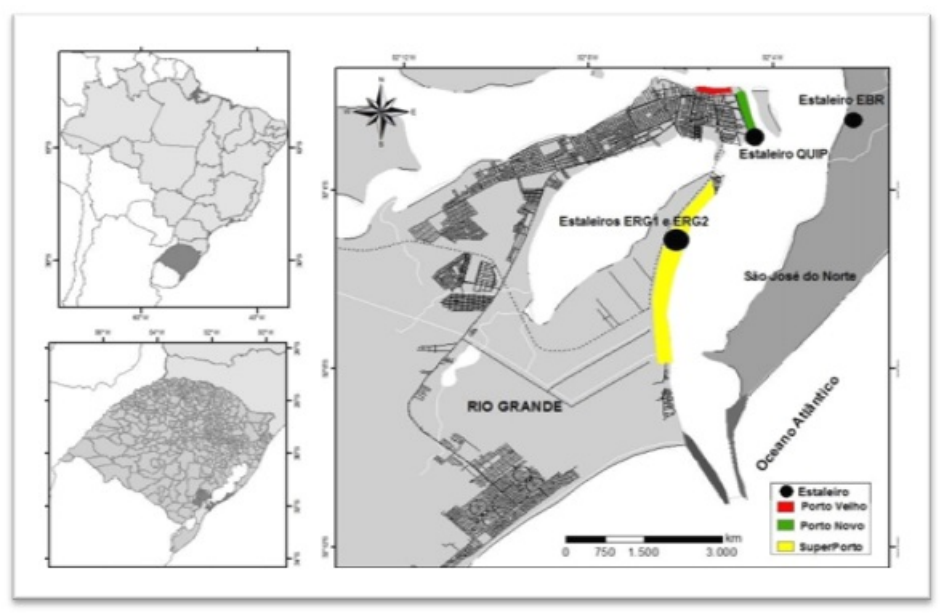

Fonte: Cunha \& Rückert (2017).

na Plataforma P-53, que se iniciou em setembro de 2007, no estaleiro QUIP, nome dado a partir do consórcio das empresas Queiroz Galvão, UTC Engenharia e IESA Óleo e Gás, que depois recebeu ainda as empresas Camargo Corrêa e a PJRM. Nesse mesmo estaleiro, também foram confeccionadas estruturas que integralizaram as construções das Plataformas P-55, P-58, P-63 que, em 2013, passaram a ser denominadas de QGI, sendo as inicias do novo grupo de acionistas, formado pelas empresas Queiroz Galvão e IESA Óleo e Gás.

Além disso, em 2006, também foi inicializado o processo de construção de uma megaestrutura para apoiar a construção naval no Brasil, o Estaleiro Rio Grande-ERG I e logo após o ERG II, dentro do mesmo complexo. Segundo Cunha \& Rückert (2017) e Domingues et al. (2008), a construção ocorreu com base na parceria das empresas Petrobras e WTorre, que detinham $80 \%$ e $20 \%$ respectivamente, do empreendimento. Tanto o ERG I quanto o ERG II eram administrados pela empresa Engevix/Ecovix. Nessas estruturas, foram construídas parcialmente as plataformas P-66, P-67 e P-68. Por fim, em 2013, o sul do RS, recebeu mais outro empreendimento naval, o Estaleiro Brasil - EBR, no município de São José do Norte, que dentre o seu portfólio de projetos, ficou responsável por confeccionar 19 módulos para a P-74.

Como destacado, durante os anos de 2006 a 2015, a região sul do RS passou por relevantes transformações, com efeitos que se traduziram em crescimento econômico e redução de pobreza, que impulsionaram o consumo de bens e serviços e também fomentaram a demanda por mão de obra qualificada, em especial para o atendimento dos anseios da indústria naval (Lima et al. 2018, Teixeira et al. 2016). Na perspectiva de amenizar a falta de mão de obra para o segmento, foram disponibilizados 25 cursos via Pronatec e um total de 615 vagas nos anos de 2013 e 2014.

Em 2013, foram disponibilizados dezesseis cursos por meio do Pronatec, destinados prioritariamente a pessoas constantes no Cadastro Único do Governo Federal e selecionados por uma equipe da Prefeitura da cidade do Rio Grande, vinculada ao Programa de Promoção do Acesso ao Mundo do Trabalho, do Ministério do Desenvolvimento Social (ACESSUAS - MDS). Para o ano de 2014, foram oferecidos nove cursos, em parceria principalmente com o Sis- 
tema Nacional de Emprego (SINE), para atender a uma necessidade de capacitação dos beneficiários do Seguro-Desemprego em Rio Grande. Em ambos os casos, houve vagas reservadas pela Secretaria de Educação do município para alunos de escolas públicas e, quando havia sobra de vagas ou desistências após o prazo de matrículas, as vagas restantes eram disponibilizadas à comunidade em geral, por meio do site do programa. No ano de 2015, o programa foi extinto no Campus, apesar de possuir alguns cursos inicialmente pactuados junto ao MEC. A Tabela 3 apresenta a relação de cursos disponibilizados pela instituição.

Segundo a Lei de Criação do Pronatec, o montante dos recursos a ser repassado para as bolsas-formação corresponde ao número de vagas pactuadas por cada instituição de ensino ofertante e, posteriormente, confirmadas como matrículas no sistema do Ministério da Educação-MEC. Os valores das bolsasformação correspondem ao custo total do curso por estudante, incluídos as mensalidades, os encargos educacionais e o eventual custeio de transporte e alimentação ao beneficiário, vedada a cobrança direta aos estudantes de taxas de matrícula, custeio de material didático ou qualquer outro valor pela prestação do serviço.

Por meio dos dados disponíveis para a pesquisa, não foi possível obter o valor total destinado à Instituição pelo Pronatec, tendo em vista que os valores foram constantemente ajustados pelo MEC de acordo com cancelamentos e evasão escolar. Porém, considerando o valor fixo hora-aluno de dez reais previsto para a realização dos cursos foi possível estimar o investimento total realizado em um montante de $\mathrm{R} \$ 1.090 .000,00$ (um milhão e noventa mil reais), reforçando a relevância da avaliação dos cursos ofertados.

Diante desse contexto, de direcionamento de recursos públicos para fins de qualificação profissional, em especial para municípios do interior do país, com falta de qualificação profissional, é que se pretende contribuir com a literatura ao se investigar se os cursos ofertados pelo IFRS, Campus Rio Grande, fizeram a diferença na inserção dos jovens inseridos no mercado de trabalho no RS. A próxima seção apresenta a metodologia e a base de dados que foram utilizadas.

\section{Dados e Estratégia empírica}

\subsection{Dados}

Para a construção da base de dados, foram utilizadas as informações disponibilizadas dos realizados pelo IFRS, Campus Rio Grande nos anos de 2013 e 2014, e também da Relação Anual de Informações Sociais-RAIS no período de 2011 a 2018. A partir dos dados dos alunos participantes e concluintes do cadastro do IFRS, Campus Rio Grande, foi possível a análise de todos os participantes dos cursos de formação profissional dessa unidade, nos dois anos de promoção dos cursos. A coleta de dados ocorreu em dois momentos: dados dos estudantes nos arquivos da instituição e dados do mercado de trabalho constantes na Relação Anual de Informações Sociais RAIS. As bases do IFRS e da RAIS permitem, respectivamente, a análise sobre a situação dos alunos quanto à conclusão ou não do curso e sua inserção no mercado de trabalho antes e após o oferecimento dos cursos de qualificação profissional.

Das 615 vagas aprovadas inicialmente para cursos FIC no Campus Rio Grande, constam no banco de dados da instituição 603 matrículas, com 250 
Tabela 3: Cursos Oferecidos no IFRS - Campus Rio Grande e custos estimados

\begin{tabular}{|l|l|c|c|c|}
\hline Ano & Curso & Carga Horária & Número de Vagas & Valor Estimado (R\$) \\
\hline 2013 & Agente de Informações Turísticas & 200 & 30 & $60.000,00$ \\
\hline 2013 & Desenhista Mecânico & 160 & 25 & $40.000,00$ \\
\hline 2013 & Desenvolvimento de Jogos Eletrônicos & 240 & 25 & $60.000,00$ \\
\hline 2013 & Eletricista Instalador Predial de Baixa Tensão & 200 & 20 & $40.000,00$ \\
\hline 2013 & Inglês Básico & 160 & 40 & $64.000,00$ \\
\hline 2013 & Instalador de Refrigeração de Climatização Doméstica & 160 & 25 & $40.000,00$ \\
\hline 2013 & Lubrificador Industrial & 160 & 20 & $32.000,00$ \\
\hline 2013 & Manipulador de Alimentos & 200 & 20 & $40.000,00$ \\
\hline 2013 & Mecânico de Ar Condicionado Automotivo & 200 & 25 & $50.000,00$ \\
\hline 2013 & Montador e Reparador de Computadores & 160 & 25 & $40.000,00$ \\
\hline 2013 & Operador de Computador & 160 & 25 & $40.000,00$ \\
\hline 2013 & Operador de Forno de Tratamento Térmico & 160 & 25 & $40.000,00$ \\
\hline 2013 & Programador Web & 200 & 25 & $50.000,00$ \\
\hline 2013 & Soldador de Oxietileno & 160 & 25 & $40.000,00$ \\
\hline 2013 & Soldador Manual de Solda Branca & 25 & $40.000,00$ \\
\hline 2013 & Traçador de Caldeiraria & 160 & 30 & $48.000,00$ \\
\hline 2014 & Agente de Informações Turísticas & 160 & 25 & $50.000,00$ \\
\hline 2014 & Desenhista Mecânico & 200 & 20 & $32.000,00$ \\
\hline 2014 & Eletricista Instalador Predial de Baixa Tensão & 160 & 20 & $40.000,00$ \\
\hline 2014 & Espanhol Básico & 200 & 25 & $40.000,00$ \\
\hline 2014 & Inglês Básico & 160 & 20 & $32.000,00$ \\
\hline 2014 & Instalador de Refrigeração e Climatização Doméstica & 160 & 20 & $32.000,00$ \\
\hline 2014 & Mecânico de Ar Condicionado Automotivo & 200 & 25 & $50.000,00$ \\
\hline 2014 & Programador Web & 200 & 25 & $50.000,00$ \\
\hline 2014 & Traçador de Caldeiraria & 160 & 25 & $40.000,00$ \\
\hline Investimento Total Estimado & & & $1.090 .000,00$ \\
\hline
\end{tabular}

Fonte: Dados da Pesquisa 
alunos concluintes e 353 desistentes, gerando uma taxa de evasão de 59\%A்qui, trata-se dos alunos desistentes, tanto aqueles que solicitaram o desligamento do curso na instituição como aqueles que não informaram a desistência em tempo hábil, mas não concluíram o curso. Do número total de matrículas, 401 foram realizadas no ano de 2013, com 183 concluintes, enquanto que 202 foram realizadas no ano de 2014, com 67 concluintes. A seguir, na Tabela 4, retrata-se a descrição das variáveis utilizadas na análise dos grupos.

Tabela 4: Descrição das Variáveis

\begin{tabular}{|c|c|}
\hline Variáveis & Descrição \\
\hline \multicolumn{2}{|l|}{ Impactadas } \\
\hline Salário-hora (R\$/hora) & $\begin{array}{l}\text { Variável contínua composta pelo } \\
\text { salário mensal nominal em } \mathrm{R} \$ \text { dividido pelo } \\
\text { número de horas trabalhadas no mês. }\end{array}$ \\
\hline $\begin{array}{l}\text { Logaritmo natural do } \\
\text { Salário-hora ( } \$ \text {-hora) }\end{array}$ & $\begin{array}{l}\text { Variável contínua composta pelo logaritmo natural } \\
\text { do salário mensal nominal em } \mathrm{R} \$ \text { dividido pelo } \\
\text { número de horas trabalhadas no mês. }\end{array}$ \\
\hline Tempo no emprego & $\begin{array}{l}\text { Variável contínua formada pelo tempo de } \\
\text { permanência em meses no atual emprego. }\end{array}$ \\
\hline Empregabilidade & $\begin{array}{l}\text { Variável binária, que assume valor igual a } 1 \text {, } \\
\text { se o trabalhador possuiu vínculo formal de trabalho } \\
\text { (carteira de trabalho assinada) e zero caso contrário. }\end{array}$ \\
\hline \multicolumn{2}{|l|}{ Controles } \\
\hline Tratados & $\begin{array}{l}\text { Variável binária que assume valor igual a } 1 \text { para } \\
\text { os grupos de trabalhadores que receberam o treinamento } \\
\text { nos anos de } 2013 \text { e } 2014 \text { e } 0 \text { caso contrário. }\end{array}$ \\
\hline Período Pós-Tratamento & $\begin{array}{l}\text { Variável binária que assume valor igual a } 1 \\
\text { para o período após o ano de } \\
2013 \text { e } 0 \text { caso contrário. }\end{array}$ \\
\hline Idade & $\begin{array}{l}\text { Variável contínua que representa a } \\
\text { idade em anos dos trabalhadores analisados. }\end{array}$ \\
\hline Homem & $\begin{array}{l}\text { Variável binária que assume valor igual a } 1 \text { para } \\
\text { indivíduos do sexo masculino e } 0 \text { caso contrário. }\end{array}$ \\
\hline Branco & $\begin{array}{l}\text { Variável binária que assume valor igual a } 1 \\
\text { para indivíduos da cor branca e } 0 \text { caso contrário. }\end{array}$ \\
\hline Possuir ensino médio & $\begin{array}{l}\text { Variável binária que assume } \\
\text { valor igual a } 1 \text { para indivíduos com } \\
\text { ensino médio completo e } 0 \text { caso contrário. }\end{array}$ \\
\hline Tamanho do estabelecimento & $\begin{array}{l}\text { Variável binária que assume valor } \\
\text { igual a } 1 \text { para empresas com mais } \\
\text { de } 50 \text { funcionários e } 0 \text { caso contrário. }\end{array}$ \\
\hline
\end{tabular}

Fonte: Elaboração própria a partir das informações da Rais e do IFRS

(2011-2018).

Tendo em vista que o treinamento a ser analisado ocorreu nos anos de 2013 e 2014, serão utilizados os dados da RAIS nos períodos de 2011 a 2018 e, com base nas informações disponibilizadas, foi possível identificar algumas covariadas que puderam ser usadas nas análises dos grupos, com informações sobre perfil do trabalhador, e também uma associada ao tipo de empresa ao qual o trabalhador está inserido. No entanto, para a variável empregabilidade, como contempla trabalhadores empregados formalmente (com carteira de trabalho assinada) e não inseridos formalmente no emprego ou sem emprego, para essa análise não foi possível contar com a análise das covariadas. 
Isso porque o grupo que se encontra não empregado formalmente, não possui informações disponíveis para serem analisadas em comparação com o outro grupo. De forma geral, a estatística descritiva das variáveis ${ }^{2}$ analisadas pode ser conferida a partir da Tabela 5 a seguir.

Tabela 5: Estatística Descritiva do banco de dados de 2011 a 2018

\begin{tabular}{|c|c|c|c|c|}
\hline \multicolumn{5}{|c|}{ Tratados } \\
\hline & \multicolumn{2}{|c|}{ Pré-Tratamento } & \multicolumn{2}{|c|}{ Pós-Tratamento } \\
\hline Variáveis & Média & Obs. & Média & Obs. \\
\hline Salário hora (R\$/hora) & 7,0989 & 255 & 9,8979 & 503 \\
\hline Ln Salário hora & 1,8225 & 252 & 2,1742 & 497 \\
\hline Idade & 32,2660 & 255 & 33,8760 & 503 \\
\hline Tempo emprego (meses) & 30,5031 & 255 & 31,4240 & 503 \\
\hline Empregado Formal & 0,3586 & 711 & 0,4244 & 1185 \\
\hline Homem & 0,2334 & 711 & 0,2455 & 1185 \\
\hline Branco & 0,2447 & 711 & 0,2700 & 1185 \\
\hline Possuir ensino Médio & 0,2053 & 711 & 0,2666 & 1185 \\
\hline T. Estabelecimento & 0,8438 & 711 & 0,8075 & 1185 \\
\hline \multicolumn{5}{|c|}{ Controles } \\
\hline & \multicolumn{2}{|c|}{ Pré-Tratamento } & \multicolumn{2}{|c|}{ Pós-Tratamento } \\
\hline & Média & Obs. & Média & Obs. \\
\hline Salário hora ( $\mathrm{R} \$ /$ hora $)$ & 6,3794 & 359 & 9,1271 & 727 \\
\hline Ln Salário hora & 1,7295 & 356 & 2,1404 & 698 \\
\hline Idade & 29,1810 & 359 & 31,9980 & 727 \\
\hline Tempo emprego (meses) & 18,8211 & 359 & 22,9669 & 727 \\
\hline Empregado Formal & 0,3499 & 1026 & 0,4251 & 1710 \\
\hline Homem & 0,1861 & 1026 & 0,2374 & 1710 \\
\hline Branco & 0,2163 & 1026 & 0,2672 & 1710 \\
\hline Possuir ensino Médio & 0,1871 & 1026 & 0,2701 & 1710 \\
\hline T. Estabelecimento & 0,8596 & 1026 & 0,8573 & 1710 \\
\hline
\end{tabular}

Fonte: Elaborado pelos autores com dados da RAIS e IFRS (2011-2018).

A partir da Tabela 5, é possível visualizar 255 correspondências na RAIS para a análise das variáveis salário-hora e tempo no emprego para o grupo de trabalhadores tratados, no período pré-tratamento e 503 no período póstratamento. Para os controles, para as mesmas variáveis, foram encontradas 359 observações para o período pré-tratamento e 727 no período póstratamento. Já para a variável $L n$ salário/hora, algumas observações foram excluídas do banco, em ambos os grupos, devido ao baixo valor do saláriohora. No que tange à variável empregabilidade, como a mesma é relacionada ao fato de os trabalhadores estarem empregados formalmente ou não, o número total de trabalhadores abrangeu os 603 trabalhadores constantes no cadastro do IFRS, Campus Rio Grande. Vale ressaltar também que foram encontrados na RAIS, em média, por ano, no período pré-tratamento, 84 trabalhadores do grupo tratado e 119 trabalhadores do grupo controle. Já no período pós-tratamento, foram encontrados, em média, ao ano, 100 trabalhadores do grupo tratado e 139 do grupo controle, todos inseridos de modo formal, o que

\footnotetext{
${ }^{2}$ Para uma análise sobre as distribuições das variáveis de interesse, por grupo, antes e depois do tratamento, conferir a Figura A.1 e A.2 do Apêndice.
} 
acaba impossibilitando a análise para os demais trabalhadores que se encontravam em trabalhos sem contrato formal de trabalho.

Quanto ao perfil dos alunos, constata-se uma similaridade entre os participantes nos dois períodos analisados. Ao analisarmos o grupo dos tratados anterior à qualificação, tem-se um salário-hora médio mensal de $\mathrm{R} \$ 7,09$, uma idade média aproximada de 32 anos, com média de 30 meses no emprego, $35,86 \%$ inseridos de modo formal, $23,34 \%$ eram homens, $24,47 \%$ brancos, $20,53 \%$ com ensino médio completo e, dos inseridos formalmente, $84,38 \%$ trabalhando em empresas com mais de 50 funcionários. Já o grupo de controle anteriormente ao tratamento tem como média de salário-hora $\mathrm{R} \$ 6,37$, aproximadamente 29 anos de idade, em média cerca de 19 meses no emprego, cerca de $35 \%$ inseridos de modo formal, $18 \%$ homens, $21,63 \%$ brancos, $18,71 \%$ com ensino médio completo e, dos inseridos formalmente, $85,96 \%$ em empresas com mais de 50 funcionários.

Em se tratando dos grupos pós-treinamento, tem-se o grupo dos tratados com média de salário-hora mensal de $\mathrm{R} \$ 9,89$, idade média aproximada de 33 anos, com média de 31 meses no emprego, 42,86\% inseridos de modo formal, $24,55 \%$ eram homens, $27,00 \%$ brancos, $26,66 \%$ com ensino médio completo e, dos inseridos formalmente, $80,75 \%$ trabalhando em empresas com mais de 50 funcionários. Já o grupo de controle, posterior ao tratamento, tem como média de salário-hora $\mathrm{R} \$ 9,12$, aproximadamente 32 anos de idade, em média cerca de 22 meses no emprego, cerca de 42,51\% inseridos de modo formal, $23,74 \%$ homens, $26,72 \%$ brancos, $27,01 \%$ com ensino médio completo e, dos inseridos formalmente, $85,73 \%$ em empresas com mais de 50 funcionários.

Posto isso, para analisar os impactos da qualificação proporcionada pelos cursos do Pronatec sobre o grupo de variáveis de interesse, será utilizado o método de Diferenças em Diferenças (DID). Essa metodologia vem sendo difundida desde a sua utilização no trabalho de Ashenfelter \& Card (1985), que avaliaram o impacto de programas de treinamento e formação de pessoal sobre os rendimentos dos trabalhadores desempregados e de baixa renda, após o período de treinamento. A seguir, detalham-se o método e também as especificações utilizadas no estudo.

\subsection{Estratégia Empírica}

A utilização do método Diferenças em Diferenças baseia-se na análise de dois grupos, o grupo tratado e grupo controle. Neste estudo, o grupo tratado é composto pelos concluintes dos cursos de qualificação profissional do IFRS Campus Rio Grande, enquanto o grupo de controle é composto por indivíduos que iniciaram o curso, mas não concluíram. O método permite que o efeito de interesse seja isolado por meio de técnicas de comparação entre eles e, para identificar o efeito do tratamento, basta comparar a diferença média entre os grupos tratados e controles.

O estimador de DID consiste no cálculo de duas subtrações, sendo que a primeira faz referência à diferença das médias da variável de resultado entre períodos anterior e posterior à realização da qualificação, tanto para o grupo tratado quanto para o grupo controle. Já a segunda subtração se refere à diferença da primeira diferença calculada para ambos os grupos.

Segundo Fogel (2012), a ideia é a de que, se as trajetórias da variável de interesse para os dois grupos são semelhantes durante o período anterior à introdução do programa, é razoável supor que também seguiriam paralela- 
mente entre os dois grupos na ausência de tratamento. Assim, qualquer desvio nas trajetórias no período posterior à intervenção se atribui ao efeito da política sobre o grupo tratado.

De acordo com Angrist \& Pischke (2008), um dos fatores mais preponderantes da metodologia DID é a capacidade de lidar com o viés de seleção por meio do controle das influências das variáveis de resultado que está associado a certas características não observáveis que são constantes no tempo. $\mathrm{O}$ estimador DID resolve esse problema, pois ao ser adicionado um grupo de controle que está exposto aos mesmos choques da variável de interesse, a dupla subtração citada acima isola os efeitos externos, considerando apenas o efeito do tratamento.

Dessa forma, seja " $\mathrm{i}$ " o indivíduo e " $\mathrm{t}$ " o período em análise, considere o seguinte modelo:

$$
Y_{i t}=\beta_{0}+\beta_{1} G_{i t}+\beta_{2} P_{i t}+\beta_{3}\left(G_{i t} \cdot P_{i t}\right)+X_{i t}^{\prime} \gamma+\varepsilon_{i t}
$$

em que $Y_{i t}$ é a variável de interesse que representa a probabilidade média de inserção formal/salário médio de reinserção, $\beta_{0}$ é a constante do modelo que representa a probabilidade média de inserção formal/salário médio de reinserção do grupo de controle antes do tratamento, $G_{i t}$ é uma variável binária indicadora de tratamento com valor igual a 1 se o indivíduo pertencer ao grupo tratado (concluinte do curso profissionalizante) e o valor igual a 0 se o indivíduo pertencer ao grupo controle (não concluinte do curso), $P_{i t}$ é uma variável indicadora de período pós e pré-tratamento, com valor igual a 1 quando " $\mathrm{t}$ " é o ano subsequente ao de realização do curso e valor 0 quando " $\mathrm{t}$ " é correspondente ao ano anterior a realização do curso, $X_{i t}^{\prime} \gamma$ é um grupo de variáveis de controle que contém variáveis de idade, faixa de escolaridade, gênero, forma de ingresso no curso e os tipos de cursos, e $\varepsilon_{i t}$ é o termo de erro.

A interação entre as duas variáveis dummies $G_{i}$ e $P_{t}$ representa o efeito da política sobre o grupo tratado, que é capturado pelo parâmetro $\beta_{3}$. É importante notar que as variáveis $G_{i}$ e $P_{t}$ aparecem no modelo (1) tanto isoladas quanto interagindo entre si. Sem a interação entre elas, as variáveis captariam apenas as diferenças das médias de $Y_{i t}$ em relação ao grupo controle e tratado e entre o período posterior e anterior à nova política. Com a interação entre essas variáveis, é possível avaliar o impacto sobre o grupo tratado no período após a política ser implantada.

$$
\begin{gathered}
E\left[Y_{i t} \mid G_{i}=1, P_{t}=1, X_{i t}^{\prime}\right]=\beta_{0}+\beta_{1}+\beta_{2}+\beta_{3}+X_{i t}^{\prime} \gamma \\
E\left[Y_{i t} \mid G_{i}=1, P_{t}=0, X_{i t}^{\prime}\right]=\beta_{0}+\beta_{1}+X_{i t}^{\prime} \gamma \\
E\left[Y_{i t} \mid G_{i}=0, P_{t}=1, X_{i t}^{\prime}\right]=\beta_{0}+\beta_{2}+X_{i t}^{\prime} \gamma \\
E\left[Y_{i t} \mid G_{i}=0, P_{t}=0, X_{i t}^{\prime}\right]=\beta_{0}+X_{i t}^{\prime} \gamma
\end{gathered}
$$


O estimador DID é dado por:

$$
\begin{gathered}
E\left[Y_{i t} \mid G_{i}=1, P_{t}=1, X_{i t}^{\prime}\right]-E\left[Y_{i t} \mid G_{i}=0, P_{t}=1, X_{i t}^{\prime}\right]- \\
\left\{E\left[Y_{i t} \mid G_{i}=1, P_{t}=0, X_{i t}^{\prime}\right]-E\left[Y_{i t} \mid G_{i}=0, P_{t}=0, X_{i t}^{\prime}\right]\right\} \\
=\left(\beta_{0}+\beta_{1}+\beta_{2}+\beta_{3}+X_{i t}^{\prime} \gamma\right)-\left(\beta_{0}+\beta_{2}+X_{i t}^{\prime} \gamma\right) \\
-\left[\left(\beta_{0}+\beta_{1}+X_{i t}^{\prime} \gamma\right)-\left(\beta_{0}+X_{i t}^{\prime} \gamma\right)\right] \\
=\beta_{3}
\end{gathered}
$$

Assim, segundo Angrist \& Pischke (2008), $\beta_{3}$ é o efeito causal de interesse sobre a variável explicativa que acompanha a interação com as duas variáveis binárias. Como já mencionado, uma das hipóteses principais desse método é a de que na ausência da realização dos cursos de qualificação, o salário médio dos integrantes dos grupos tratados e controles evolui de forma semelhante, ou seja, ambos os grupos têm tendências paralelas. Assim, quanto maior o valor do coeficiente $\beta_{3}$, maior o impacto do choque exógeno da política sobre as variáveis em análise no modelo. Do contrário, quanto menor o coeficiente $\beta_{3}$, menor o impacto da política.

A fim de promover uma análise de robustez ao efeito médio do tratamento sobre os tratados, estimou-se $\beta_{3}$ de quatro formas funcionais distintas, sendo elas: (i) estimadores para dados em painel com controle de efeito-fixo de indivíduo e de tendência temporal; (ii) estimadores para dados em painel com controle de efeito-fixo de indivíduos, tendência temporal e covariadas ; (iii) estimadores para dados em painel com controle de efeito-fixo de indivíduos, tendência temporal, covariadas e efeitos heterogêneos de exposição após ao tratamento; e (iv) estimadores desenvolvidos a partir de pareamento amostral em variáveis observáveis no período pré-tratamento.

Primeiramente, estimou-se a seguinte equação:

$$
Y_{i t}=\alpha+\beta G_{i} \cdot P_{t}+\theta_{i}+v_{t}+\varepsilon_{i t}
$$

em que o subscrito it denota o trabalhador $i$ no período $t$. $Y_{i t}$ representa as variáveis dependentes de interesse, probabilidade de reinserção formal, saláriohora de reinserção, logaritmo natural do salário-hora de reinserção e tempo no emprego. Já $P_{t}$ é uma variável binária de tempo, que assume $P=1$ para períodos de $t$ após a realização dos cursos de qualificação e $P=0$ para $t$ períodos anteriores, enquanto $G_{i}$ representa os grupos de comparação, em que $G=1$ para o grupo de trabalhadores $i$ beneficiários pelo programa e $G=0$ para os trabalhadores $i$ não beneficiários, ou seja, o grupo de controle. $\theta_{i}$ indica o efeito fixo de indivíduo, que serve para controlar algo individual de cada trabalhador e que é invariante no tempo, como dedicação, força de vontade em apreender, dentre outras, que são características individuais e não observáveis, que se não controladas podem estar nos resíduos, gerando viés nos estimadores. Além disso, utilizou-se o controle de tendência temporal, representada por $v_{t}$, com a finalidade de controlar eventos ao longo do tempo que pudessem causar maior ou menor facilidade de inserção dos grupos no mercado de trabalho. Por fim, $\beta$ é o parâmetro de interesse, o qual indica o efeito causal do programa sobre os tratados e $\varepsilon_{i t}$ o componente residual. 
A segunda especificação utilizada na análise pode ser vista abaixo:

$$
Y_{i t}=\alpha+\beta G_{i} \cdot P_{t}+X_{i t}^{\prime} \gamma+\theta_{i}+v_{t}+\varepsilon_{i t}
$$

Na equação (10), temos a especificação que compreende as estimativas de todos os parâmetros destacados na equação (9) mais a inserção de um vetor $X_{i t}^{\prime} \gamma$ de variáveis observáveis de indivíduos, representadas por: (i) raça; (ii) escolaridade; (iii) idade; (iv) gênero; e (v) tamanho do estabelecimento. Esse vetor acaba por depurar o componente residual ao retirar efeitos de características individuais observáveis que podem influenciar na variável de resultado e que estariam no resíduo.

A terceira especificação utilizada na análise leva em consideração as estimativas de todos os parâmetros destacados na equação (10) com o acréscimo de dummies que capturam o efeito do tratamento em diferentes momentos após o tratamento. Ou seja, com controle diferenciado de anos após o tratamento sobre o grupo de trabalhadores tratados, ela é definida da seguinte maneira:

$$
Y_{i t}=\alpha+\sum_{a=1}^{A=5} \beta_{a} \cdot G_{i} \cdot P_{a}+X_{i t}^{\prime} \gamma+\theta_{i}+v_{t}+\varepsilon_{i t}
$$

em que $Y_{i t}$ denota as variáveis dependentes de interesse (empregabilidade, salário-hora, logaritmo natural do salário hora e tempo no emprego) para o trabalhador $i$, no ano $t ; G_{i}$ denota uma variável dummy que assume valor igual a 1 para os indivíduos treinados $i$; $P_{a}$ assume valor igual a 1 para cada ano a após o treinamento (2013 e 2014); $\beta_{a}$ captura o efeito heterogêneo do treinamento para cada ano $a=1$ até $a=5 ; X_{i t}$ é um vetor de covariadas de indivíduos $i$ no ano $t ; \theta_{i}$ é um efeito fixo de indivíduo, que captura as características não observadas e fixas ao longo do tempo de cada indivíduo $i$; $v_{t}$ busca captar diferentes tendências ao longo do tempo $t$; $\varepsilon_{i t}$ é um termo de erro aleatório.

Por fim, utilizou-se o estimador que combina o método Propensity Score Matching - PSM com o método Diferenças em Diferenças. Esse estimador permite a flexibilização da hipótese do PSM de que a seleção dos grupos deve ocorrer apenas via fatores observáveis e, assim, a seleção dos grupos de comparação pode ocorrer via características não observáveis, porém que estas últimas sejam constantes no tempo. Além disso, os pesos são inversamente proporcionais à diferença entre o escore de propensão dos indivíduos tratados e não tratados (Cerulli 2015).

O parâmetro estimado ao combinar ambas as metodologias pode ser visualizado como:

$$
\widehat{\beta}_{D I D-P S M}=\frac{1}{N_{1}} \sum_{i \in t}\left[\left(Y_{i, t=1}^{\text {Trat }}-Y_{i, t=0}^{\text {Trat }}\right)-\sum_{j \in C(i)} h(i, j) \cdot\left(Y_{j, t=1}^{\text {Cont }}-Y_{j, t=0}^{\text {Cont }}\right)\right]
$$

sendo que a variável $t$ determina o período em que a unidade de observação $i$ se encontra em cada momento do tempo, antes e depois do tratamento. As variáveis Trat e Cont representam se o indivíduo faz parte do grupo de tratamento ou de controle, respectivamente, o termo $h(i, j)$ representa os pesos 
derivados da aplicação do escore de propensão e $C(i)$ é a vizinhança do grupo de controle considerada ao realizar o pareamento. Na próxima seção, são apresentados os resultados encontrados para todas as especificações destacadas.

\section{Resultados}

Na Tabela 6, são apresentados os resultados para a análise do efeito do Programa sobre o salário-hora, considerando as quatro especificações realizadas: (i) estimadores para dados em painel com controle de efeito-fixo de indivíduo e de tendência temporal; (ii) estimadores para dados em painel com controle de efeito-fixo de indivíduos, tendência temporal e covariadas ; (iii) estimadores para dados em painel com controle de efeito-fixo de indivíduos, tendência temporal, covariadas e efeitos heterogêneos de exposição após ao tratamento; e (iv) estimadores desenvolvidos a partir de pareamento amostral em variáveis observáveis no período pré-tratamento.

A partir da análise da Tabela 6, não foi possível evidenciar, em nenhuma das especificações, efeito, estatisticamente significativo, da participação nos cursos de qualificação sobre a variável dependente, salário-hora, para os grupos de trabalhadores que participaram das qualificações promovidas via Pronatec, no Campus Rio Grande do IFRS. No entanto, algumas variáveis de controle se mostraram dentro do sinal de esperado, como idade, indicando uma relação inversamente proporcional às varrições no salário-hora e tamanho do estabelecimento, relacionado diretamente proporcional às variações no salário-hora. A fim de explorar ainda mais a análise para a variável saláriohora, também foi analisada a variável em logaritmo natural (Ln), conforme destacado a seguir, na Tabela 7 .

Como ressaltado, na Tabela 7 , os valores dos parâmetros de interesse não sofreram alterações estatisticamente significativas, reforçando o fato de que não houve efeito da participação nos cursos de qualificação sobre a variável dependente, Ln salário-hora, para os grupos de trabalhadores que participaram das qualificações promovidas via Pronatec, no Campus Rio Grande do IFRS. Porém, foi possível observar a relação do logaritmo do salário-hora com uma das variáveis de controle que se mostrou estatisticamente significativa, a associada ao tamanho do estabelecimento, relacionando-se de maneira diretamente proporcional às variações no salário-hora. Esse resultado corrobora o fato de que empresas maiores tendem a promover maiores salários, algo evidenciado pela literatura e com distintas interpretações. Seguindo na linha dos incentivos, é possível relacionar esse resultado como sendo decorrente do fato de que empresas de maior porte possuem maiores custos de monitoramento, o que compensaria promover ganhos salariais mais elevados para reduzir o comportamento considerado não ideal ou shirking por parte dos seus trabalhadores. Além dessa explicação, é possível destacar, também, a narrativa apresentada por Abraham \& Farber (1987), no qual ressaltam o fato de que empresas maiores possuem melhores condições institucionais, que geram maior estabilidade no quadro de funcionários, promovendo um ambiente de maior ascensão profissional, gerando assim ganhos de produtividade, que permitem remunerar melhor os seus funcionários ${ }^{3}$. A seguir, na Tabela 8 , discutem-se

\footnotetext{
${ }^{3}$ Além dessas duas, existem outras como as destacadas por Brown et al. (1990), que ressaltam o fato de que empresas maiores teriam lucros de monopólio e seriam alvo de sindicatos. A fim de reduzir os custos de judicialização, as empresas teriam incentivos em remunerar melhor seus
} 
Tabela 6: Resultados sobre salário-hora

\begin{tabular}{|c|c|c|c|c|}
\hline \multirow[b]{2}{*}{ Variáveis } & (i) & (ii) & (iii) & (iv) \\
\hline & Salário-hora & Salário-hora & Salário-hora & Salário-hora \\
\hline \multirow[t]{2}{*}{ Efeito médio } & 0,254 & 0,272 & & 1,594 \\
\hline & $(0,695)$ & $(0,697)$ & & $(1,132)$ \\
\hline \multicolumn{5}{|l|}{ Efeito heterogêneo } \\
\hline \multirow[t]{2}{*}{1 ano tratado } & & & $-0,455$ & \\
\hline & & & $(0,439)$ & \\
\hline \multirow[t]{2}{*}{2 anos tratado } & & & $-0,211$ & \\
\hline & & & $(0,397)$ & \\
\hline \multirow[t]{2}{*}{3 anos tratado } & & & $-1,419$ & \\
\hline & & & $(0,866)$ & \\
\hline \multirow[t]{2}{*}{4 anos tratado } & & & 0,257 & \\
\hline & & & $(0,886)$ & \\
\hline \multirow[t]{2}{*}{5 anos tratado } & & & 1,334 & \\
\hline & & & $(1,602)$ & \\
\hline \multirow[t]{2}{*}{ Homem } & & $-1,052$ & $-1,217$ & \\
\hline & & $(1,210)$ & $(1,223)$ & \\
\hline \multirow[t]{2}{*}{ Branco } & & 0,104 & 0,0482 & \\
\hline & & $(0,375)$ & $(0,365)$ & \\
\hline \multirow[t]{2}{*}{ Ensino médio } & & 0,00290 & $-0,0285$ & \\
\hline & & $(0,290)$ & $(0,295)$ & \\
\hline \multirow[t]{2}{*}{ Tamanho estabelecimento } & & $0,769^{* *}$ & $0,775^{\star *}$ & \\
\hline & & $(0,313)$ & $(0,313)$ & \\
\hline \multirow[t]{2}{*}{ Idade } & & $-0,0945^{* * *}$ & $-0,0887^{* * *}$ & \\
\hline & & $(0,0228)$ & $(0,0228)$ & \\
\hline \multirow[t]{2}{*}{ Constante } & $5,157^{* * *}$ & $7,959^{* * *}$ & $7,933^{* * *}$ & $5,623^{* * *}$ \\
\hline & $(0,339)$ & $(1,171)$ & $(1,194)$ & $(0,524)$ \\
\hline Observações & 1.844 & 1.844 & 1.844 & 681 \\
\hline $\mathrm{R} 2$ & 0,188 & 0,193 & 0,199 & 0,166 \\
\hline Número de cpf & 488 & 488 & 488 & 136 \\
\hline EF indivíduo & $\operatorname{sim}$ & $\operatorname{sim}$ & $\operatorname{sim}$ & $\operatorname{sim}$ \\
\hline EF ano & $\operatorname{sim}$ & $\operatorname{sim}$ & $\operatorname{sim}$ & $\operatorname{sim}$ \\
\hline Pareamento" & não & não & não & $\operatorname{sim}$ \\
\hline
\end{tabular}

Notas: Pareamento realizado pelo método do Propensity Score Matching - Vizinho mais próximo (Nearest Neighbor Matching) no ano de 2012. Variáveis utilizadas para o pareamento: homem, branco, ensino médio, tamanho do estabelecimento e idade; erros-padrão robustos entre parênteses; ${ }^{* * *} \mathrm{p}<0,01,{ }^{* *} \mathrm{p}<0,05,{ }^{*} \mathrm{p}<0,1$. A distribuição dos escores de propensão podem ser visualizados na Figura A.3 do Apêndice. 
Tabela 7: Resultados sobre Ln do Salário-hora

\begin{tabular}{|c|c|c|c|c|}
\hline Variáveis & $\begin{array}{c}\text { (i) } \\
\text { Ln Salário }\end{array}$ & $\begin{array}{c}\text { (ii) } \\
\text { Ln Salário }\end{array}$ & $\begin{array}{c}\text { (iii) } \\
\text { Ln Salário }\end{array}$ & $\begin{array}{c}\text { (iv) } \\
\text { Ln Salário }\end{array}$ \\
\hline Efeito médio & $\begin{array}{c}-0,0605 \\
(0,0438)\end{array}$ & $\begin{array}{c}-0,0573 \\
(0,0431)\end{array}$ & & $\begin{array}{r}-0,0179 \\
(0,066)\end{array}$ \\
\hline \multicolumn{5}{|l|}{ Efeito heterogêneo } \\
\hline 1 ano tratado & & & $\begin{array}{l}-0,0124 \\
(0,0340)\end{array}$ & \\
\hline 2 anos tratado & & & $\begin{array}{l}-0,0155 \\
(0,0328)\end{array}$ & \\
\hline 3 anos tratado & & & $\begin{array}{l}-0,0380 \\
(0,0463)\end{array}$ & \\
\hline 4 anos tratado & & & $\begin{array}{c}-0,00110 \\
(0,0481)\end{array}$ & \\
\hline 5 anos tratado & & & $\begin{array}{l}-0,0159 \\
(0,0681)\end{array}$ & \\
\hline Homem & & $\begin{array}{c}-0,0332 \\
(0,116)\end{array}$ & $\begin{array}{c}-0,0386 \\
(0,117)\end{array}$ & \\
\hline Branco & & $\begin{array}{c}0,0365 \\
(0,0297)\end{array}$ & $\begin{array}{c}0,0346 \\
(0,0299)\end{array}$ & \\
\hline Ensino médio & & $\begin{array}{c}0,0305 \\
(0,0290)\end{array}$ & $\begin{array}{c}0,0293 \\
(0,0292)\end{array}$ & \\
\hline Tamanho estabelecimento & & $\begin{array}{l}0,0710^{* *} \\
(0,0296)\end{array}$ & $\begin{array}{l}0,0712^{* *} \\
(0,0297)\end{array}$ & \\
\hline Idade & & $\begin{array}{l}-0,00326 \\
(0,00586)\end{array}$ & $\begin{array}{l}-0,00308 \\
(0,00595)\end{array}$ & \\
\hline Constante & $\begin{array}{l}1,587^{* * *} \\
(0,0278)\end{array}$ & $\begin{array}{c}1,619^{* * *} \\
(0,181)\end{array}$ & $\begin{array}{c}1,618^{* * *} \\
(0,183)\end{array}$ & $\begin{array}{c}1,624^{* * *} \\
(0,040)\end{array}$ \\
\hline Observações & 1.803 & 1.803 & 1.803 & 662 \\
\hline R2 & 0,406 & 0,412 & 0,413 & 0,445 \\
\hline Número de cpfs & 488 & 488 & 488 & 136 \\
\hline EF indivíduo & $\operatorname{sim}$ & Sim & $\operatorname{sim}$ & $\operatorname{sim}$ \\
\hline EF ano & $\operatorname{sim}$ & Sim & $\operatorname{sim}$ & $\operatorname{sim}$ \\
\hline Pareamento" & não & Não & não & $\operatorname{sim}$ \\
\hline
\end{tabular}

Notas: Pareamento realizado pelo método do Propensity Score Matching - Vizinho mais próximo (Nearest Neighbor Matching) no ano de 2012. Variáveis utilizadas para o pareamento: homem, branco, ensino médio, tamanho do estabelecimento e idade; erros-padrão robustos entre parênteses; ${ }^{* *} \mathrm{p}<0,01$, ${ }^{* *} \mathrm{p}<0,05,{ }^{*} \mathrm{p}<0,1$. A distribuição dos escores de propensão podem ser visualizados na Figura A.3 do Apêndice. 
os resultados para tempo no emprego.

Tabela 8: Resultados sobre Tempo no Emprego

\begin{tabular}{|c|c|c|c|c|}
\hline Variáveis & $\begin{array}{c}(\mathrm{i}) \\
\text { Tempo } \\
\text { Emprego }\end{array}$ & $\begin{array}{c}\text { (ii) } \\
\text { Tempo } \\
\text { Emprego }\end{array}$ & $\begin{array}{c}\text { (iii) } \\
\text { Tempo } \\
\text { Emprego }\end{array}$ & $\begin{array}{c}\text { (iv) } \\
\text { Tempo } \\
\text { Emprego }\end{array}$ \\
\hline Efeito médio & $\begin{array}{l}-4,714 \\
(4,025)\end{array}$ & $\begin{array}{l}-4,709 \\
(4,005)\end{array}$ & & $\begin{array}{l}-3,859 \\
(6,320)\end{array}$ \\
\hline Efeito heterogêneo & & & & \\
\hline 1 ano tratado & & & $\begin{array}{l}-0,222 \\
(2,619)\end{array}$ & \\
\hline 2 anos tratado & & & $\begin{array}{l}-1,874 \\
(1,195)\end{array}$ & \\
\hline 3 anos tratado & & & $\begin{array}{c}2,553 \\
(1,931)\end{array}$ & \\
\hline 4 anos tratado & & & $\begin{array}{l}-3,124 \\
(3,246)\end{array}$ & \\
\hline 5 anos tratado & & & $\begin{array}{l}-2,611 \\
(5,298)\end{array}$ & \\
\hline Homem & & $\begin{array}{c}7,127 \\
(4,780)\end{array}$ & $\begin{array}{c}7,152 \\
(4,827)\end{array}$ & \\
\hline Branco & & $\begin{array}{c}4,625^{* * *} \\
(1,384)\end{array}$ & $\begin{array}{c}4,606^{* * *} \\
(1,371)\end{array}$ & \\
\hline Ensino médio & & $\begin{array}{l}-2,184 \\
(1,781)\end{array}$ & $\begin{array}{l}-2,192 \\
(1,759)\end{array}$ & \\
\hline Tamanho estabelecimento & & $\begin{array}{c}2,180 \\
(1,570)\end{array}$ & $\begin{array}{c}2,186 \\
(1,574)\end{array}$ & \\
\hline Idade & & $\begin{array}{c}0,989^{*} \\
(0,589)\end{array}$ & $\begin{array}{c}0,989^{*} \\
(0,593)\end{array}$ & \\
\hline Constante & $\begin{array}{c}23,05^{* * *} \\
(2,073)\end{array}$ & $\begin{array}{l}-12,36 \\
(17,49)\end{array}$ & $\begin{array}{l}-12,38 \\
(17,62)\end{array}$ & \\
\hline Observações & 1.844 & 1.844 & 1.844 & 681 \\
\hline R2 & 0,080 & 0,092 & 0,094 & 0,056 \\
\hline Número de cpf & 488 & 488 & 488 & 136 \\
\hline EF indivíduos & Sim & $\operatorname{sim}$ & $\operatorname{sim}$ & Sim \\
\hline EF ano & Sim & $\operatorname{sim}$ & $\operatorname{sim}$ & Sim \\
\hline Pareamento" & Não & Não & Não & Sim \\
\hline
\end{tabular}

Notas: Pareamento realizado pelo método do Propensity Score Matching - Vizinho mais próximo (Nearest Neighbor Matching) no ano de 2012. Variáveis utilizadas para o pareamento: homem, branco, ensino médio, tamanho do estabelecimento e idade; erros-padrão robustos entre parênteses; ${ }^{* * *} \mathrm{p}<0,01,{ }^{* *} \mathrm{p}<0,05,{ }^{*} \mathrm{p}<0,1$. A distribuição dos escores de propensão podem ser visualizados na Figura A.3 do Apêndice.

Com base na Tabela 8, é possível verificar que os valores dos parâmetros de interesse não sofreram alterações estatisticamente significativas, reforçando o fato de que não houve o efeito da participação nos cursos de qualificação sobre a variável de interesse, tempo de permanência no emprego, para os grupos de trabalhadores que participaram das qualificações promovidas via Pronatec, no Campus Rio Grande do IFRS. No entanto, duas variáveis de controle se mostraram diretamente relacionadas ao tempo no emprego, sendo elas Raça e Idade. No quesito Raça, o fato de o trabalhador ser branco em relação aos

funcionários. 
demais aumenta em média quatro meses e meio no emprego atual, e cada ano a mais de idade aumenta em média praticamente um mês a mais no emprego atual.

Tabela 9: Resultado sobre Empregabilidade

\begin{tabular}{lcc}
\hline Variáveis & $\begin{array}{c}(\mathrm{i}) \\
\text { Empregado }\end{array}$ & $\begin{array}{c}(\mathrm{ii}) \\
\text { Empregado }\end{array}$ \\
\hline Efeito médio & 0,0110 & \\
& $(0,0318)$ & \\
Efeito heterôgeno & & 0,0120 \\
1 ano tratado & & $(0,0395)$ \\
& & 0,0193 \\
2 anos tratado & & $(0,0371)$ \\
3 anos tratado & & 0,0120 \\
& & $(0,0381)$ \\
4 anos tratado & & $-0,0821^{*}$ \\
& & $(0,0420)$ \\
anos tratado & & 0,0623 \\
Constante & & $(0,0479)$ \\
Observações & $0,307^{* * *}$ & $0,307^{* *}$ \\
R2 & $(0,0167)$ & $(0,0167)$ \\
Número de cpf & 4.632 & 4.632 \\
EF indivíduo & 0,014 & 0,015 \\
EF ano & 579 & 579 \\
Fonte: Resultados da pesquisa. Nota: Robust standard \\
errors in parentheses ${ }^{* * *} \mathrm{p}<0,01,{ }^{* *} \mathrm{p}<0,05,{ }^{*} \mathrm{p}<0,1$ \\
\end{tabular}

Para o caso da empregabilidade, Tabela 9, foram estimadas duas especificações lineares, uma com efeito médio do tratamento sobre os tratados considerando todo o período pós-tratamento de 2014 a 2018, e a outra com efeitos heterogêneos de tempo após o treinamento. Em ambas as especificações, não foi possível encontrar resultados estatisticamente significativos, o que nos permite concluir que o cursos realizados não serviram para aumentar a chances de inserção profissional de modo formal entre os seus beneficiários. Os resultados encontrados corroboram com os obtidos por Barbosa Filho et al. (2016), os quais também evidenciam que o Pronatec Bolsa-Formação na modalidade FIC não foi efetivo no sentido de aumentar o salário de reinserção, nem empregabilidade de seus egressos no mercado de trabalho formal. No entanto, os autores destacam que o programa pode servir como sinalizador do perfil do trabalhador ao mercado de trabalho, dada a disposição revelada, em querer participar de um curso profissionalizante. Além disso, vale destacar que no período pós-treinamento, 2014, o mercado de trabalho brasileiro iniciou um processo de retratação, em especial o do segmento naval, que a partir de denúncias de corrupção passou a ter uma queda em suas atividades, sendo os estaleiros instalados no sul do RS diretamente impactados, com projetos de confecções de plataformas suspensos e transferidos para países asiáticos, com destaque para China.

Por outro lado, Casson (2015) mostra que o programa teve um efeito sig- 
nificativo na renda daqueles que concluíram um curso técnico em relação aos que não concluíram. Tal resultado favorável do programa também é encontrado no Relatório Técnico elaborado pelo Ministério do Desenvolvimento Social - MDS (2018), o qual indica um impacto positivo do Pronatec no aumento da empregabilidade formal de seus participantes, principalmente entre os que também são beneficiários do Programa Bolsa-Família e residentes no Nordeste do país.

Um aspecto relevante destacado por Silva (2015), que pode explicar a ausência de efeitos encontrados no presente trabalho, está relacionado ao fato de os cursos do Pronatec serem de curta duração, não apresentando tempo hábil para a qualificação, de fato, da mão de obra. Nesse sentido, Barbosa Filho et al. (2016) acrescentam que os cursos FIC funcionaram mais para atrair trabalhadores com disposição para encontrar novos empregos do que como um programa com capacidade de ampliar a produtividade dos trabalhadores. No entanto, se os trabalhadores não se tornam mais qualificados, seguindo a lógica de Wambugu (2003), não aumentam sua produtividade e consequentemente o seu nível salarial. Conforme Barros et al. (2001), a falta de qualificação individual contribui também para a desqualificação geral do mercado de trabalho, gerando impactos adversos sobre o nível de desenvolvimento do país, o que reforça a necessidade da manutenção desse tipo de programa, porém, talvez, com cursos de maior duração, maior diversidade e alinhamento com o mercado de trabalho local ou mesmo regional, para que assim os trabalhadores treinados possam exercer sua capacitação em postos de trabalhos que exijam o perfil de profissionais capacitados pelos cursos. Além disso, ressalta-se a importância de se manter um acompanhamento desses profissionais, sendo dessa formal possível a realização de avaliações periódicas da eficácia do programa sobre a vida profissional desses trabalhadores, para que se consiga uma melhor gestão dos mesmos em escalas menos agregadas, como regionais e municipais.

\section{Considerações Finais}

O presente estudo teve por objetivo avaliar o efeito da qualificação profissional sobre a performance profissional dos trabalhadores que concluíram os cursos vinculados ao Pronatec, disponibilizados pelo IFRS no Campus Rio Grande-RS. Em especial, foram analisados os efeitos sobre salário de reinserção, tempo de emprego e empregabilidade, levando em consideração o período de 2011 e 2018. Para tanto, foi realizado um estudo de caso com trabalhadores matriculados em cursos do Pronatec no IFRS, Campus Rio Grande, dividindo-os em dois grupos: (i) grupo de tratamento composto pelos alunos concluintes e o (ii) grupo de controle formado pelos alunos matriculados, porém desistentes.

Para tanto, foi utilizado o Método de Diferenças em Diferenças com quatro especificações distintas: (i) estimadores para dados em painel com controle de efeito-fixo de indivíduo e de tendência temporal; (ii) estimadores para dados em painel com controle de efeito-fixo de indivíduos, tendência temporal e covariadas; (iii) estimadores para dados em painel com controle de efeito-fixo de indivíduos, tendência temporal, covariadas e efeitos heterogêneos de exposição após ao tratamento; e (iv) estimadores desenvolvidos a partir de pareamento amostral em variáveis observáveis no período pré-tratamento. A par- 
tir dos resultados não foi possível encontrar evidências da relação causal do efeito do treinamento sobre os ganhos salariais, tempo no emprego e empregabilidade dos trabalhadores que concluíram os cursos em relação aos demais. Porém, os resultados vão ao encontro de outros trabalhos da revisão empírica estudada, o qual apontam problemas de estrutura no Pronatec, gerando limitações já verificadas em programas antecessores, como o Planfor, por exemplo, o que põe em xeque a forma de condução desse tipo de programa de qualificação no país.

Vale ressaltar algumas importantes limitações do trabalho. Primeiramente, focou-se na avaliação do mercado de trabalho formal. Muitas pessoas não registradas na RAIS estão ocupadas no mercado informal, trabalham como pessoa jurídica, são empregadas domésticas ou são autônomas, o que impossibilita a análise devido à falta de informações individuais sobre o mercado de trabalho. Em segundo lugar, analisamos os impactos no curto prazo e em um momento de recessão. Mesmo que seja generalizada, para ambos os grupos, ela pode estar influenciando de maneira mais forte o mercado de trabalho foco dos cursos de qualificação, como no caso o segmento naval. Por fim, a existência de poucas observações impossibilitou a avaliação mais detalhada por curso, porém acredita-se que essas limitações não impactaram significativamente nos resultados destacados.

\section{Agradecimentos}

Esta pesquisa contou com o Auxílio Financeiro a Projeto Educacional ou de Pesquisa (Auxpe) 3217 do Pró-Integração (edital 55/2013) da Comissão de Aperfeiçoamento de Pessoal do Nível Superior (Capes) e do Programa Primeiros Projetos (ARD/PPP 2014) da Fundação de Amparo à Pesquisa do Rio Grande do Sul (FAPERGS) e do Conselho Nacional de Desenvolvimento Científico e Tecnológico (CNPq). Além disso, os autores agradecem a CoordenaçãoGeral de Cadastros, Identificação Profissional e Estudos - CGCIPE pela disponibilização dos dados da RAIS.

\section{Referências Bibliográficas}

Abraham, K. \& Farber, H. (1987). Job duration, seniority, and earnings. The American Economic Review, Nashville, v. 77, p. 278.

Angrist, J. D. \& Pischke, J. (2008). Mostly Harmless Econometrics: an Empiricist's Companion. Princeton: Princeton University Press.

Ashenfelter, O. \& Card, D. (1985). Using the longitudinal structure of earnings to estimate the effect of training programs. Review of Economics and Statistics, Cambridge, v.67, p. 648-660.

Barbosa Filho, F. H., Porto, R. \& Liberato, D. (2016). Pronatec BolsaFormação: Uma Avaliação Inicial sobre Reinserção no Mercado de Trabalho Formal. In: XLIII Encontro Nacional de Economia da ANPEC. Florianópolis: ANPEC.

Barros, R. P., Cossio, M. B. \& Teles, J. L. (2001). A eficácia das políticas de trabalho e renda no combate à pobreza. In: Velloso, J. P. R. (org.) Soluções para a Questão do Emprego - Fórum Nacional. São Paulo: José Olympio. 
Betcherman, G., Olivas, K. \& Dar, A. (2004). Impacts of Active Labor Market Programs: New Evidence from Evaluations with Particular Attention to Developing and Transition Countries. Washington, DC: World Bank. (Social Protection Discussion Paper Series n. 0402).

Brasil (2011). Lei n. 12.513, de 26 de outubro de 2011. Institui o Programa Nacional de Acesso ao Ensino Técnico e Emprego (Pronatec); e dá outras providências. Diário Oficial da República Federativa do Brasil, Brasília. Disponível em: http://www.planalto.gov.br/ccivil_03/_ato20112014/2011/lei/112513.htm. Acesso em 24 abr. 2017.

Brown, C., Hamilton, J. T. \& Medoff, J. (1990). Employers Large and Small. Cambridge: Harvard University Press.

Camargo, J. M. (2004). Política Social No Brasil: prioridades erradas, incentivos perversos. São Paulo em Perspectiva, São Paulo, v. 18, p. 68-77.

Cassiolato, M. M. \& Garcia, R. C. (2014). Pronatec: múltiplos arranjos e ações para ampliar o acesso à educação profissional. Brasília: IPEA. (Texto de Discussão do IPEA n. 1919).

Casson, R. J. (2015). Análise Custo/Benefício do Programa Pronatec do Governo Federal. 2015. Dissertação (Mestrado em Economia) - Insper, São Paulo.

Cerulli, G. (2015). Econometrics evaluation of socio-economics programs. In: Baltagi, B. H.; Hong, Y.; Koop, G.; Krämer, W.; Mátyás L. (orgs.) Advanced Studies in Theorical and Applied Econometrics. Berlin: Springer. v. 49.

Corseuil, C. H., Foguel, M. \& Tomelin, L. F. (2018). Uma avaliação de impacto de um programa de qualificação profissional na empresa sobre a inserção dos jovens no mercado de trabalho formal. Brasília: IPEA. (Texto de Discussão do IPEA n. 2347).

Cunha, R. \& Rückert, A. (2017). Polo Naval Offshore de Rio Grande: estratégias políticas e a formação de um complexo da produção naval. Geosul, Florianópolis, v. 10, p. 239-260.

Domingues, M., Carvalho, D. \& Menezes, G. (2008). Polo Naval do Rio Grande: Primeiros insights sobre a formação de um cluster portuário marítimo. In: IV Seminário Internacional sobre Desenvolvimento Regional. Rio de Janeiro: UNISC.

Fernandes, R., Menezes-Filho, N. A. \& Zylberstajn, H. (2000). Avaliando o PLANFOR: O programa do Sindicato dos Metalúrgicos de São Paulo. São Paulo: IPE/USP. (Texto para Discussão IPE/USP).

Firpo, S., Fogel, M. \& Jales, H. (2014). Evaluating the impact of stratified randomized experiments with an application to a Brazilian public training program. In: World Congress of the Econometric Society. Montreal: Econometric Society.

Fogel, M. (2012). Avaliação econômica de projetos sociais. São Paulo: Fundação Itaú Social. 
Friedlander, D., Greenberg, D. H. \& Robins, P. (1997). Evaluating government training programs for the economically disadvantaged. Journal of Economic Literature, Nashville, v. 35, p. 1809-1855.

Greenberg, D. H. (2003). A meta-analysis of government-sponsored training programs. Industrial and Labor Relations Review, Ithaca, v. 57, p. 31-53.

Heckman, J., Lalonde, R. \& Smith, J. (1999). The economics and econometrics of active labor market programs. Handbook of Labor Economics, Amsterdam, v. 3, p. 1865-2097.

Ibarrarán, P. \& Shady, D. R. (2009). Evaluating the impact of job training programmes in Latin America: evidence from IDB funded operations. Journal of Development Effectiveness, Delhi, v. 1, p. 195-216.

Kluve, J. (2006). The Effectiveness of European Active Labour Market Policy. Bonn: IZA. (Discussion Paper Series n. 2018).

Lechner, M. \& Melly, B. (2007). Earnings Effects of Training Programs. Bonn: IZA. (Discussion Paper n. 2926).

Lima, A. F. R., Ribeiro, F. G. \& Teixeira, G. S. (2020). Job qualification programs for young apprentices: an analysis in the Brazilian Midwest. Education + Training, Bingley, v. 62, p. 677-692.

Lima, S. B., Teixeira, G. S., Abdallah, P. R. \& Halmenschlager, V. (2018). Efeito da política de mobilização do setor naval no Rio Grande do Sul: uma análise sobre a arrecadação municipal. RACE, New York, v. 17, p. 449-474.

Lopo, R. M. (2015). Do macro-discurso de pujança ao choque cultura: alguns dos impactos do Polo Naval na cidade de Rio Grande. In: Machado, C. R. S.; Santos, C. F. ; Mascarello, M. A. (orgs.) Conflitos Ambientais e Urbanos: casos do extremo sul do Brasil. Porto Alegre: Evangraf.

Martin, J. \& Grubb, D. (2001). What works and for whom: a review of OECD countries' experiences with active labour market policies. Swedish Economic Policy Review, Lund, v. 8, p. 9-56.

Ministério da Educação - MEC (2020). Governo Federal. Disponível em: https://www.gov.br/mec/pt-br.

Oliveira, G. R., Oliveira, F. R., Terra, R. \& Zoghbi, A. C. (2019). Efeitos do programa de qualificação profissional Bolsa Futuro na empregabilidade e salário dos trabalhadores. Pesquisa e Planejamento Econômico, Rio de Janeiro, v. 49 , p. $69-98$.

Silva, D. M. (2015). Desvelando o Pronatec: Uma Avaliação Política do Programa. 2015. Dissertação (Mestrado em Educação) - Centro de Educação, Universidade Federal do Rio Grande do Norte, Natal.

Silva, P. V. (2016). O PRONATEC-FIC no Rio Grande do Sul: quem é o seu participante? 2016. Dissertação (Pós-Graduação em Educação) - Faculdade de Educação, Universidade Federal do Rio Grande do Sul, Porto Alegre. 
Teixeira, G. \& Balbinotto Neto, G. (2016). Seguro-desemprego brasileiro e salário de reinserção: análise empírica com regressão com descontinuidade e propensity score matching. Nova Economia, Belo Horizonte, v. 26, p. 943-980.

Teixeira, G. S., Balbinotto Neto, G. \& Leivas, P. H. S. (2020). Evidence on rule manipulation and moral hazard in the Brazilian unemployment insurance program. International Journal of Social Science Studies, Beaverton, v. 8, p. 6778.

Teixeira, G. S., Ribeiro, F. G., Abdallah, P. R. \& Gonçalves, R. R. (2016). Indústria da construção naval e economia regional: uma análise via diferenças em diferenças para os municípios inseridos no Corede Sul. Ensaios FEE, Porto Alegre, v. 37, p. 459-488.

Wambugu, A. (2003). Essays on Earnings and Human Capital in Kenya. 2003. Thesis (Doctoral Degree in Economics) - School of Business, Economics and Law, Göteborg University, Sweden.

\section{Apêndice A}

Figura A.1: Distribuições das Variáveis Impactadas - Tratados
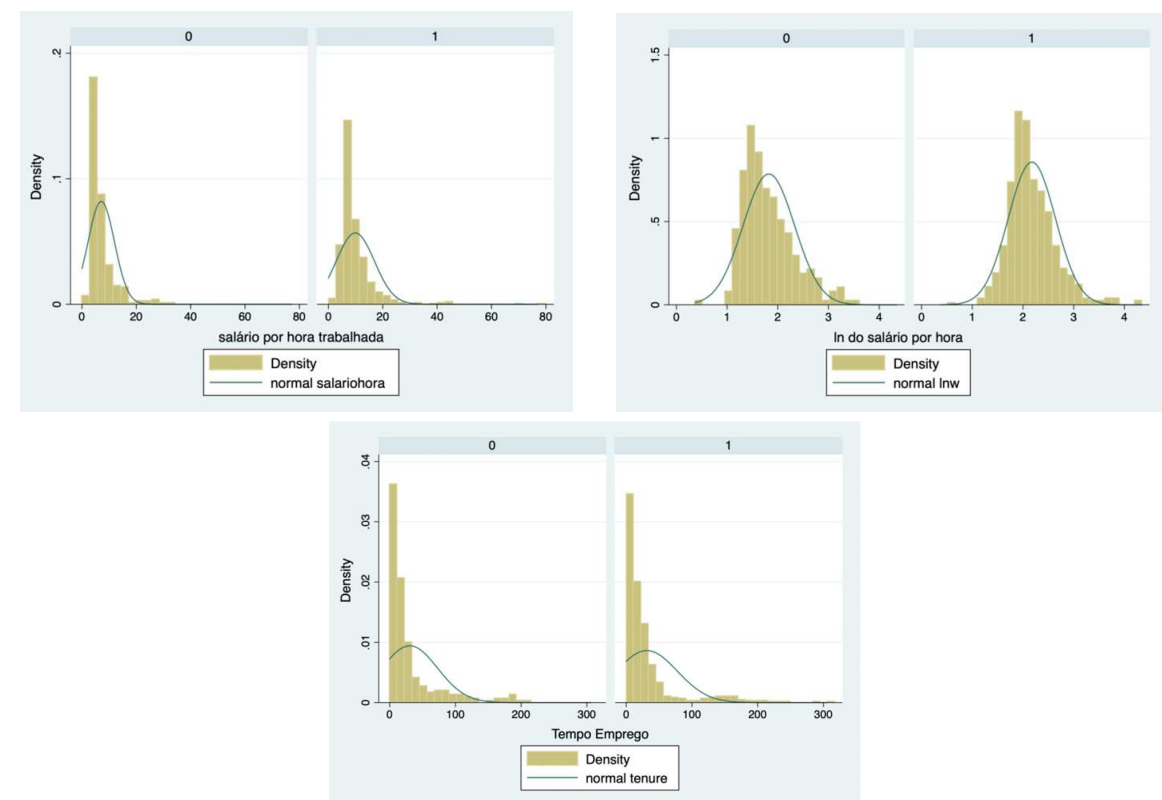

Fonte: Resultados da pesquisa. 
Figura A.2: Distribuições das Variáveis Impactadas - Controles
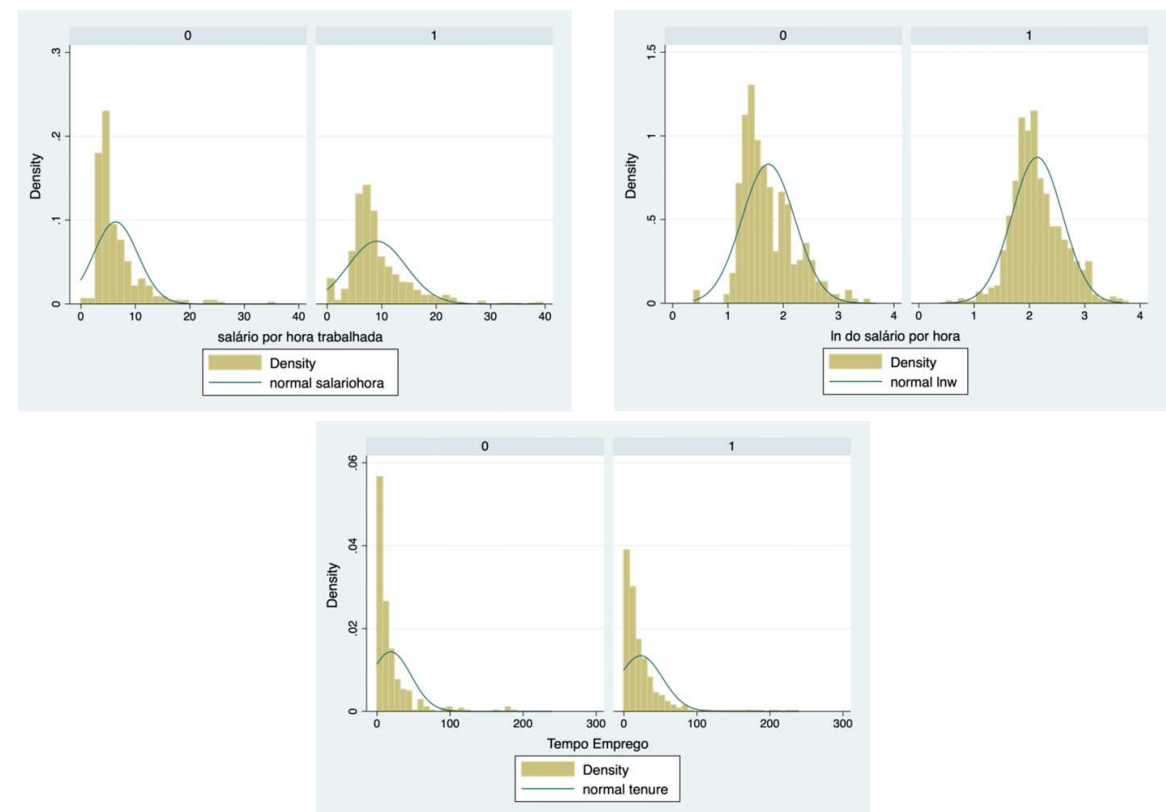

Fonte: Resultados da pesquisa.

Figura A.3: Função Distribuição do Score de Propensão da Amostra Pareada

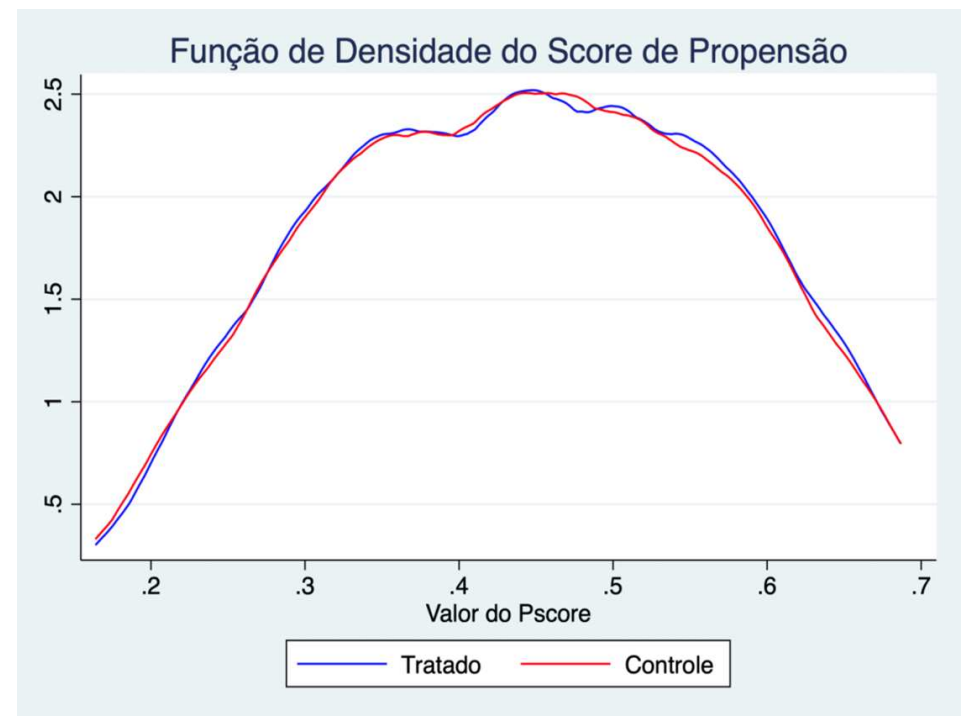

Fonte: Resultados da pesquisa. 